\title{
Thermodynamic and Experimental Analysis of an Ammonia-Water Absorption Chiller
}

\author{
Dingfeng Kong, Jianhua Liu, Liang Zhang, Hang He, Zhiyun Fang \\ School of Energy and Power Engineering, University of Shanghai for Science and Technology, Shanghai, China \\ E-mail: kongdingfeng2002@163.com \\ Received August 4, 2010; revised September 15, 2010; accepted October 16, 2010
}

\begin{abstract}
A single stage ammonia-water absorption chiller with complete condensation is designed, built and tested. The apparatus is designed for a cooling capacity of $2814 \mathrm{~W}$, which is obtained using electric heater as heating source. The thermodynamic models have been derived using the First and Second Laws. Calculated results are compared with experimental data. The results show that the cooling capacity of experimental apparatus is found between 1900 and $2200 \mathrm{~W}$ with the actual coefficient of performance (COP) between 0.32 and 0.36 . The contribution of the components to internal entropy production is analyzed. It shows that the larger irreversibility is caused by spanning the largest temperature and dissipated thermal energy by heat transfer losses at the generator and evaporator. In the experimentation, the low pressure is lower than the designed value. This is a consequence of a large capacity in the falling film absorber which performs as expected. This decreases the evaporation pressure, and the evaporating temperature could be reduced to the designed value.
\end{abstract}

Keywords: Absorption Chiller, Ammonia-Water, Thermodynamic Modeling, Experimental, Performance

\section{Introduction}

Widespread efforts are currently underway to utilize available energy resources efficiently by minimizing waste energy and develop replacements for the traditionally refrigerants (CFCs and HCFCs), which contribute to ozone depletion and greenhouse warming. Absorption chillers which are heat-powered refrigeration systems have got more and more attention, due to the recognition of rational utilization of energy and the concerns about ecological problem.

The ammonia-water mixture is environmental friendly, which is the only working pair currently used for refrigeration purposes in absorption systems, and despite of the new mixtures under investigation, the ammonia-water mixture is the only one with a clear future [1]. The principle of the absorption is providing the necessary pressure difference between the vaporizing and condensing processes, which alternately condenses under high pressure in the condenser by rejecting heat to the environment and vaporizes under low pressure in the evaporator by absorbing heat from the medium being cooled. Ammonia-water absorption chillers have been widely used

The research is funded by The Innovation Fund Project for Graduate Student of Shanghai (JWCXSL0901) in many occasions [2].

Amount of work associated with theoretical and experimental analysis of the commercial absorption chillers, using ammonia-water as the working fluid, is available in the literature $[3,4]$. There are three classical kinds of endoreversible modeling in previous approach [5-9]. K. C. $\mathrm{Ng}$ et al. presented an explicit irreversible thermodynamic model, which considered external and internal losses, to permit easy determination of optimal operating conditions of chiller, as well as a predictive and diagnostic capability [10-14]. Via comparison with actual data of an absorption chiller, firstly, it clearly demonstrated that all endoreversible models fail to capture part of the key losses which contribute to the chiller COP. By accounting for only the external irreversibilities, they over predict the chiller COP by as much as $160-180 \%$. Secondly, endoreversible models portray an incorrect trend for COP in the upper region of the characteristic plot, which also predicts no maximum for the COP at the practical cooling range of absorption chillers. The reasons for this is all endoreversible models ignore the presence of internal losses stemming from heat and mass transfer in the generator and absorber, internal regeneration and throttling. A key element of accounting for internal entropy production is the use of a process average temperature to 
analyze energy and entropy flows. An accurate process average temperature is essential to perform chiller diagnostics, or predict chiller performance under different operating conditions, or evaluate efficiency improvements that would derive from diminishing a given source of irreversibility. H. T. Chua et al. developed a general definition of the process average temperature. It is based on the method of computing for the process average temperature for the evaporator, condenser, generator and absorber [15].

However, most of the research is carried out with commercially fashioned chillers that have been specifically designed as an air-cooled system. To investigate the system characteristics being consistent with the reality, an experimental apparatus is designed and fabricated, using the irreversible thermodynamic model. All aircooled components are replaced by water-cooled components, and variation of some operating parameters should be carried out. The model considers both the external and internal losses in ammonia-water absorption chiller to accurately predict the chiller COP at its nominal range of cooling capacity.

\section{Experimental Testing of the Apparatus}

\subsection{Description of the Apparatus}

An experimental apparatus has been designed and built to study the performance of a single stage ammoniawater system with complete condensation. A schematic diagram and a photograph of the experimental apparatus are shown in Figure 1. The major components are the generator, vertical sieve tray tower with complete condensation (VST), absorber, condenser, evaporator, solution heat exchanger (SHE), subcooler, ammonia fluid reservoir (AFR), solution fluid reservoir (SFR), pump and refrigerant expansion device (RED) and weak solution expansion device (SED).

The ammonia-water mixture is heated in the generator

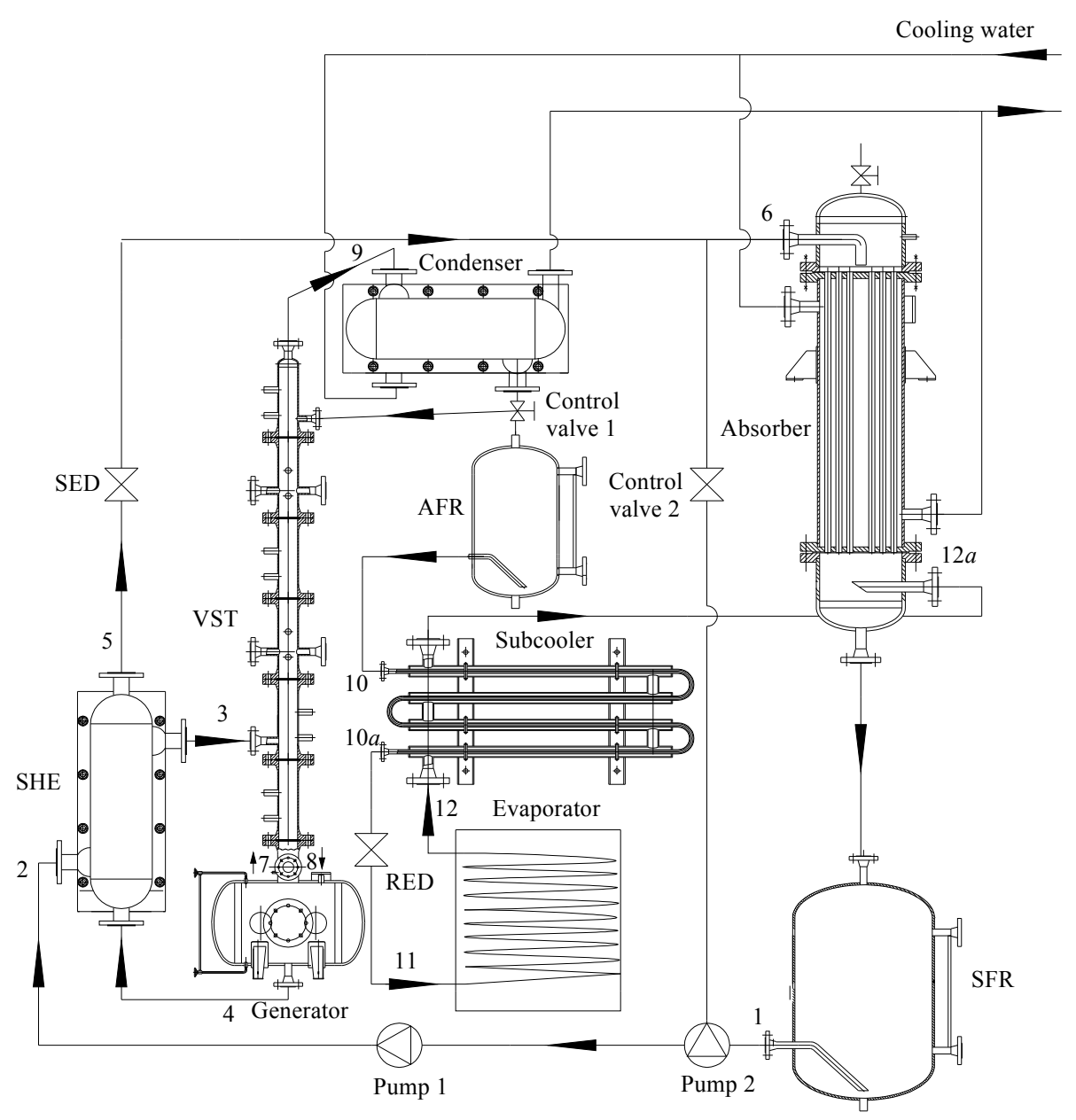

Figure 1. A schematic diagram of the apparatus. State points are same in figures and tables below. 
by electric heater, which is equipped with three sets of electric resistances, $3000 \mathrm{~W}$ each. The heater power can be adjusted and controlled. The heat power reaches values of up to $9000 \mathrm{~W}$. An electro connecting pressure gauge is installed in the generator. For normal operating conditions, the system high pressure side is approximately 14 bar. The electric heater is turned off under the conditions of more than 23 bar. Then ammonia vapour is separated, but it is mixed up with fractions of water vapour. The purification process is carried out by a VST, where a counter-current contact is established between an upward vapour flow and a downward liquid flow.

The VST is built with the seamless tube in Steel ASTM 1020 of $68 \mathrm{~mm}$ inner diameter and a total length of $1800 \mathrm{~mm}$, divided into 6 sections, in order to disassemble conveniently, $300 \mathrm{~mm}$ each. Two pairs of $10 \mathrm{~mm}$ thick Pyrex glasses are installed in each section mounted on $102 \mathrm{~mm}$ from bottom, which allow checking if flooding inside the VST occurs. To reduce heat losses to the environment, the stripping section of VST and generator are insulated with a mineral wool preformed pipe of thickness $15 \mathrm{~mm}$.

The vapour enriched in ammonia content leaving the VST is condensed in a plate type condenser, cooled by water, which removes heat from the gas mixture and the vapour is condensed to a liquid. After the vapour is completely condensed, the liquid leaves the condenser and passes to the subcooler. The subcooler is a shell and tube heat exchanger, which reduces the temperature of the liquid. When the liquid mixture leaves the subcooler, the pressure drops as it passes through a RED into the evaporator. After leaving the evaporator, the vapour is further heated as passing through the subcooler to the absorber. The high pressure weak solution leaving the generator enters a SHE. Finally, the weak solution passes through a SED and enters into the absorber with the refrigerant vapour coming from the subcooler. Then the vapour is absorbed into the weak solution from the generator in the water-cooled absorber, which is a falling film type. The strong solution is now at the lower cycle pressure, and it must be sent to the stripping section. This is achieved by a diaphragm pump. Then the cycle is completed.

\subsection{Data acquisition System}

The experimental apparatus has been equipped with an acquisition data system based on a PC and an acquisition data card. Refrigerant, absorbent temperatures are collected from PT-100 probe with accuracy of $\pm 0.15 \mathrm{~K}$. Pressures are obtained from piezoelectric transducers with an accuracy of \pm 0.2 bar. The cooling water flow rate in the condenser and absorber is measured by means of a rotary flowmeter with an accuracy of $\pm 0.2 \%$. The rest of flow rate in the apparatus is measured by means of a Coriolis sensor with accuracy of $\pm 0.1 \%$ and electromagnetic turbine sensors with an accuracy of $\pm 0.3 \%$. Concentrations of the binary mixture are determined by titration with an uncertainty of $\pm 4 \%$. Before experimentation, the entire instruments have been calibrated. Evaporation and condensation temperatures, high and low pressures, and concentration are recorded.

\subsection{Experimental Procedure}

After the system is evacuated with a vacuum pump, the SFR and generator are filled with 1201 of aqueous solution of ammonia with mass concentration of 0.40. All valves on the apparatus are closed. The required experimental generation heat value is of $6000 \mathrm{~W}$. In order to generate the needed temperature, it is needed to adjust the power of electric heater. The rate of heating is controlled below $363 \mathrm{~K} / \mathrm{h}$. When the generation pressure is raised in the scope of 6-7 bar, the SED and pump 1 are opened to start the cycle of ammonia-water solution. The cooling water valve of condenser is opened, when generation pressure gradually equals to condensing pressure. Then the valve through the vapour on the top of VST is opened. The cooling water flow is adjusted to control pressure of VST whenever necessary. The quantity of reflux is controlled to avoid for weeping or flooding. The RED is opened as the liquid mixture passes into the evaporator. The suction valve of saturated vapour leaving from evaporator on the absorber is opened, while the cooling water valve of absorber is opened. The absorbent pressure and absorbent temperature are controlled to designed values by adjusting cooling water flow on absorber. The cooling capacity is determined using a calorimetric measuring procedure based on the regulations of the thermal balance. In each test, a $120 \mathrm{~kg}$ of fresh water in a thermal balance water box is kept at $293 \mathrm{~K}$. An aquarium pump is used to circulate the water. Once the apparatus has reached the steady state, all test data are recorded by the data acquisition system.

\section{Mathematical Model}

A mathematical model is developed to analyze the performance of the experimental system. Temperatures and pressures of working fluid are based on designed values. Water and ammonia properties are obtained from standard properties of pure substances table in the ASHRAE [16]. Specifically, ammonia-water properties are based on procedures developed by Tillner-Roth and Friend [17]. 


\subsection{First and Second Law Analysis}

The thermodynamic models of components ensure energy balance, mass balance and entropy production applying the Second Law of Thermodynamics. With the expression for heat transfer rate $Q_{i}$, the thermal conductance of component is calculated from

$$
Q_{i}=\sum_{\alpha=1}^{j}\left[\left(m_{\alpha} \cdot h_{\alpha}\right)_{\text {in }}+\left(m_{\alpha} \cdot h_{\alpha}\right)_{\text {out }}\right]
$$

$S_{i}^{\text {int }}$ represents the summations of the entropy generation due to heat and mass transfer in the certain component.

$$
S_{i}^{\mathrm{int}}=\sum_{\text {out }} m_{i} s_{i}-\sum_{\text {in }} m_{i} s_{i}-Q_{i} / T_{i}
$$

From Equation (2), an accurate process average temperature $T_{i}$ is essential as defining and deriving $S_{i}^{\text {int }}$, which translates into accurate evaluation of heat exchanger effective thermal conductance. $T_{i}$ is intent upon performing chiller diagnostics, or predicting chiller performance under different operating conditions, or evaluating efficiency improvements that would derive from diminishing a given source of irreversibility.

$$
T_{i}=\frac{\int d H}{\int(d H / T)}
$$

From Equation (3), $T_{i}$ is computed from the properly weighted piecewise compilation of measured temperatures along nonisothermal paths. In practical situations, the thermodynamic system is expected to relate to as an effective blackbox which can be probed from the outside only, i.e., for which only nonintrusive measurements at the inlets and outlets are realistic. These claims were demonstrated in Ref. 18. So the correct process average temperature should be calculated using experimental measurements and basic thermodynamic analysis for ammonia-water absorption chiller. All the terms on the right hand side of Equation (3) can be computed from the thermodynamic properties of the refrigerant if the local pressures and temperatures at the inlets and outlets are known.

\subsection{Assumptions}

- It is saturated state, when the weak solution leaves the generator at the generation temperature.

- The refrigerant leaves the condenser at the condensing temperature as saturated liquid.

- The refrigerant leaving the evaporator is evaporated completely as saturated vapour.

- The strong solution leaves the absorber at the absorbent temperature as saturated liquid.

- The energy balances do not contain the heat losses in the VST, so the effect of VST is neglected.

Applying Equations (1) and (2) for each component, the heat transfer rates and entropy generation are summarized in Table 1 below.

\subsection{System Thermal Balance}

The internal energy and the entropy of the working fluids in the absorption cycle are written as follows:

$$
\begin{aligned}
& S_{\mathrm{tot}}^{\mathrm{int}}=S_{\mathrm{g}}^{\mathrm{int}}+S_{\mathrm{c}}^{\mathrm{int}}+S_{\mathrm{a}}^{\mathrm{int}}+S_{\mathrm{e}}^{\mathrm{int}}+S_{\mathrm{SHE}}^{\mathrm{int}}+S_{\mathrm{sc}}^{\mathrm{int}} \\
& +S_{\mathrm{P}}^{\mathrm{int}}+S_{\mathrm{SED}}^{\mathrm{int}}+S_{\mathrm{RED}}^{\mathrm{int}}
\end{aligned}
$$

\subsection{Coefficient of Performance}

The general refrigeration system can be considered as a perfectly reversible system, the net refrigerating effect is the heat absorbed by the refrigerant in the evaporator. The theoretical COP is given by

$$
\mathrm{COP}_{\mathrm{th}}=\frac{Q_{\mathrm{e}}}{Q_{\mathrm{g}}}
$$

In the absorption refrigeration system, the total energy supplied to the system is the total of the heat supplied in the generator and work done by the pump. The actual COP of the ammonia-water absorption chiller is calculated from

$$
\mathrm{COP}=\frac{Q_{\mathrm{e}}}{Q_{\mathrm{g}}+W_{\mathrm{P}}}
$$

\section{Discussion}

\subsection{Comparison between Actual and Calculated Performance}

Table 2 tabulates the summary of heat transfer rates and performance parameters of the apparatus. The actual COP decreases reaching values of $90 \%$ at the theoretical COP of 0.469. Therefore the work of the pump can not be neglected when considering the performance of absorption chiller.

Referring to the Figure 2, the actual results are found to lie between $75 \%$ and $85 \%$ of the calculated values. The difference may result from heat loss from the generator, low concentration and large resistance of refrigerant and supercooling degree does not meet the requirements, etc. When deciding which one is main factor, multiply the surface area of the generator with the difference between the temperature of the surrounding and that of the generator. Then divide the result with the ad- 
Table 1. Summary of first and second law relations for each component of the apparatus.

\begin{tabular}{|c|c|c|c|}
\hline Component & Mass balance & Energy balance & Entropy generation \\
\hline Generator & $\begin{array}{c}m_{4}+m_{7}=m_{8} \\
m_{4} x_{4}+m_{7} x_{7}=m_{8} x_{8}\end{array}$ & $Q_{\mathrm{g}}=m_{4} h_{4}+m_{7} h_{7}-m_{8} h_{8}$ & $S_{\mathrm{g}}^{\mathrm{int}}=m_{4} S_{4}+m_{7} S_{7}-m_{8} s_{8}-Q_{\mathrm{g}} / T_{\mathrm{g}}$ \\
\hline Condenser & $m_{9}=m_{10}$ & $Q_{\mathrm{c}}=m_{9}\left(h_{9}-\mathrm{h}_{10}\right)$ & $S_{\mathrm{c}}^{\mathrm{int}}=m_{9}\left(S_{10}-S_{9}\right)+Q_{\mathrm{c}} / T_{\mathrm{c}}$ \\
\hline Absorber & $\begin{array}{c}m_{6}+m_{12 \mathrm{a}}=m_{1} \\
m_{6} x_{6}+m_{12 \mathrm{a}} x_{12 \mathrm{a}}=m_{1} x_{1}\end{array}$ & $Q_{\mathrm{a}}=m_{6} h_{6}+m_{12 a} h_{12 a}-m_{1} h_{1}$ & $S_{\mathrm{a}}^{\mathrm{int}}=m_{1} S_{1}-m_{6} S_{6}-m_{12 a} S_{12 a}+Q_{\mathrm{a}} / T_{\mathrm{a}}$ \\
\hline Evaporator & $m_{11}=m_{12}$ & $Q_{\mathrm{c}}=m_{12}\left(h_{12}-\mathrm{h}_{11}\right)$ & $S_{\mathrm{c}}^{\text {int }}=m_{12}\left(S_{12}-S_{11}\right)-Q_{\mathrm{c}} / T_{\mathrm{c}}$ \\
\hline SHE & $m_{2}=m_{3 .} \cdot m_{4}=m_{5}$ & $Q_{\mathrm{SHE}}=m_{3}\left(h_{3}-h_{2}\right)=m_{4}\left(h_{4}-h_{5}\right)$ & $S_{\mathrm{SHE}}^{\mathrm{int}}=m_{2}\left(s_{2}+S_{4}-S_{3}-S_{5}\right)$ \\
\hline Subcooler & $m_{10}=m_{10 \mathrm{a}} \cdot m_{12}=m_{12 \mathrm{a}}$ & $Q_{\mathrm{sc}}=m_{10}\left(h_{10}-h_{10 \mathrm{a}}\right)=m_{12}\left(h_{12 \mathrm{a}}-h_{12}\right)$ & $S_{\mathrm{sc}}^{\mathrm{int}}=m_{10}\left(S_{10 \mathrm{a}}+S_{12 \mathrm{a}}-S_{10}-S_{12}\right)$ \\
\hline Pump 1 & $m_{1}=m_{2}$ & $W_{\mathrm{P}}=m_{2} h_{2}-m_{1} h_{1}$ & $S_{\mathrm{P}}^{\mathrm{int}}=m_{2}\left(s_{2}-s_{1}\right)+W_{\mathrm{P}}$ \\
\hline SED & $m_{5}=m_{6}$ & $Q_{\mathrm{RED}}=m_{5} h_{5}=m_{6} h_{6}$ & $S_{\mathrm{SED}}^{\mathrm{int}}=m_{5}\left(s_{6}-s_{5}\right)$ \\
\hline RED & $m_{10 \mathrm{a}}=m_{11}$ & $Q_{\mathrm{RED}}=m_{10 \mathrm{a}} h_{10 \mathrm{a}}=m_{11} h_{11}$ & $S_{\mathrm{RED}}^{\mathrm{int}}=m_{10 \mathrm{a}}\left(s_{11}-S_{10 \mathrm{a}}\right)$ \\
\hline
\end{tabular}

Table 2. Properties of the various state points for the chiller.

\begin{tabular}{|c|c|c|c|c|c|c|}
\hline State & $h(\mathrm{~kJ} / \mathrm{kg})$ & $m(\mathrm{~kg} / \mathrm{s})$ & $P$ (bar) & $T(\mathbf{K})$ & $x(\mathrm{~kg} / \mathrm{kg})$ & $s(\mathrm{~kJ} / \mathrm{kg} \cdot \mathrm{K})$ \\
\hline 1 & 65 & 0.01756 & 2.06 & 309 & 0.40 & 0.7647 \\
\hline 2 & 65 & 0.01756 & 14.37 & 309 & 0.40 & 0.6493 \\
\hline 3 & 326 & 0.01756 & 14.37 & 363 & 0.40 & 1.854 \\
\hline 4 & 430 & 0.01481 & 14.37 & 393 & 0.29 & 1.858 \\
\hline 5 & 100 & 0.01481 & 14.37 & 319 & 0.29 & 0.649 \\
\hline 6 & 100 & 0.01481 & 2.06 & 319 & 0.29 & 0.6497 \\
\hline 7 & 1830 & 0.00274 & 14.37 & 368 & 0.95 & 5.6577 \\
\hline 8 & 350 & 0.01781 & 14.37 & 368 & 0.40 & 1.4752 \\
\hline 9 & 1680 & 0.00274 & 14.32 & 318 & 0.998 & 5.9196 \\
\hline 10 & 500 & 0.00274 & 14.32 & 318 & 0.998 & 1.7853 \\
\hline $10 \mathrm{a}$ & 414 & 0.00274 & 14.32 & 313 & 0.998 & 1.6321 \\
\hline 11 & 414 & 0.00274 & 2.36 & 258 & 0.998 & 1.6415 \\
\hline 12 & 1440 & 0.00274 & 2.36 & 258 & 0.998 & 6.3315 \\
\hline $12 \mathrm{a}$ & 1526 & 0.00274 & 2.36 & 293 & 0.998 & 6.5272 \\
\hline
\end{tabular}

Summary of heat transfer rates and performance parameters of the apparatus COP $=0.424 \quad \mathrm{COP}_{\mathrm{th}}=0.467 \quad W_{\mathrm{P}}=636 \mathrm{~W} \quad Q_{\mathrm{sc}}=236 \mathrm{~W} \quad Q_{\mathrm{SHE}}=4300 \mathrm{~W}$ $Q_{\mathrm{g}}=6000 \mathrm{~W} \quad Q_{\mathrm{e}}=2814 \mathrm{~W} \quad Q_{\mathrm{a}}=4526 \mathrm{~W} \quad Q_{\mathrm{c}}=4100 \mathrm{~W}$.

dition of the ratio of the thickness of the generator and thermal conductivity of the generator and that of the thickness of the insulation material and thermal conductivity of the insulation material. It can be seen that, the heat loss from the generator is the main reason of the difference.

In the experimentation, adjust the flow of refrigerant by changing the opening of RED to ensure the constant temperature level of the generator along with increasing the heat load. The calculated cooling capacity increases almost linearly with the generator heat input. It is discovered that to operate the experimental apparatus there is a minimum generator input (around $4800 \mathrm{~W}$ ). When the heat input is lower than the minimum value, the system is not able to produce any cooling capacity. To obtain a rectifying effect, a minimum vapour generated is required. Then the vapour rises through the VST and flows counter-currently with a liquid introduced at the 


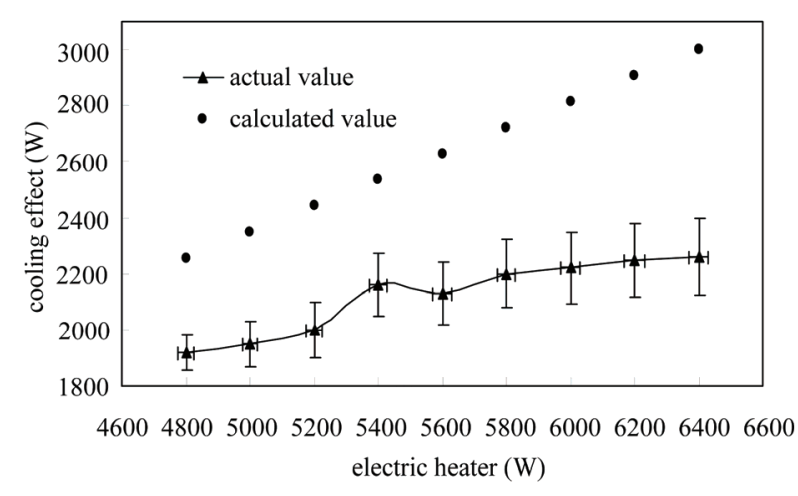

Figure 2. Comparison between actual and calculated cooling capacity.

top of the VST. When the heat input increases beyond the minimum value, it can produce cooling capacity since there is enough liquid ammonia throttled and entered the evaporator. Further increase in heat input produces a higher cooling capacity as more pure refrigerant vapour is generated. This also causes COP to increase. Then the liquid refrigerant completely evaporates in the evaporator and maximum cooling capacity is obtained. From the curve, it can be seen that when the heat input continues to increase around $6000 \mathrm{~W}$, the cooling capacity increases with a lower rate. This implies that the levelling off cooling capacity is limited due to the fixed condensing pressure, temperature limitations, or rising need for rectification.

\subsection{Discussion of the Results and Structure Improvement}

The measured pressures, temperatures, mass flow rate and mass concentration of the component for steady state operation are listed in Table 3, along with the computed states at each point.

In the experimentation, the low pressure is lower than the designed value. This is a consequence of a large capacity in the falling film absorber which performs as expected. This decreases the evaporation pressure, and the evaporating temperature could be reduced to the designed value. Considering the actual results are found to lie between $75 \%$ and $85 \%$ of the calculated values, the contribution of the components to internal entropy production based on a general macroscopic equation is analyzed. Table 4 presents the contribution of the components depicted in Figure 1 to internal entropy production based on the above mentioned entropy production equations.

When calculated results are compared with actual values, this should show how losses for different devices occur and how the system could be modified. The analy-
Table 3. Measured and computed properties of the chiller.

\begin{tabular}{cccc}
\hline \multicolumn{2}{c}{ Parameters (Point) } & Computed & Measured \\
\hline & Weak solution (4) & 0.29 & $0.2919 \pm 0.0061$ \\
$x(\mathrm{~kg} / \mathrm{kg})$ & Strong solution (1) & 0.40 & $0.4138 \pm 0.0070$ \\
& Refrigerant (9) & 0.998 & $0.9689 \pm 0.0012$ \\
& Inlet Generator & 14.37 & $14.035 \pm 0.281$ \\
$P(\mathrm{bar})$ & Condenser & 14.32 & $14.00 \pm 0.455$ \\
& Inlet Evaporator & 2.36 & $1.95 \pm 0.09$ \\
& Weak solution (4) & 0.01481 & $0.015 \pm 0.0002$ \\
$m(\mathrm{~kg} / \mathrm{s})$ & Strong solution (1) & 0.01756 & $0.01756 \pm 0.0009$ \\
& Refrigerant (9) & 0.00274 & $0.00199 \pm 0.0001$ \\
& Outlet VST & 318 & $321 \pm 0.31$ \\
& Outlet RED & 258 & $259 \pm 0.03$ \\
& Evaporator & 293 & $298 \pm 0.15$ \\
\hline
\end{tabular}

Table 4. Contribution of the components to internal entropy production.

\begin{tabular}{ccc}
\hline Components & \multicolumn{1}{c}{$S_{i}^{\text {int }}$} & $S_{i}^{\text {int }} / S_{\text {tot }}^{\text {int }}$ \\
\hline Generator & 1.4786 & 0.2377 \\
Condenser & 1.8978 & 0.3051 \\
Absorber & 0.1543 & 0.0248 \\
Evaporator & 1.9436 & 0.3125 \\
SHE & 0.0755 & 0.0121 \\
Subcooler & 0.1164 & 0.0187 \\
SED & 0.0104 & 0.0017 \\
RED & 0.0258 & 0.0042 \\
Pump 1 & 0.5176 & 0.0832 \\
$S_{\text {tot }}^{\text {int }}$ & 6.2199 & 1 \\
\hline
\end{tabular}

sis shows that the generator contributes to the entropy generation, approximately $24 \%$ of the total internal entropy production. Thermal energy is dissipated by heat transfer losses at the generator. The irreversibility in the generator results from spanning the largest temperature and low utilization of electric heater. The utilization factor of the electric heating is low and the degree of the irreversibility is high, which leads to the increase of internal entropy. Other heating methods in the generator should be developed to deduce irreversibility, such as exhaust gas, solar energy and solar energy. The entropy generation of the evaporator contributes $31 \%$ to the total entropy generation. Insulation condition for evaporator 
may be improved to diminish irreversibility, to promote COP and cooling capacity.

The entropy generation of the condenser contributes $30 \%$ to the total entropy generation. Counter-current condenser causes a larger temperature differences leading to a bigger entropy generation, in spite of high heat transfer efficiency.

When the thermodynamic state point remains in 10a instead of 10 with the subcooler before throttling, the cooling capacity is $9 \%$ more than the values without a subcooler. The entropy generation of the subcooler contributes $1.9 \%$ to the total entropy generation. It is concluded that, if the apparatus with a subcooler, the benefits outweigh its drawbacks.

Simultaneous heat and mass transfer in the absorber contributes only about $2.5 \%$ to the internal entropy production of the chiller. The result also presents the contribution of the RED and SED on the chiller's performance, and it is only a significant, though not a dominating mechanism.

\section{Conclusions}

A mathematical model is developed to analyze the performance of a single stage ammonia-water absorption refrigeration chiller with complete condensation. The apparatus is tested with heat input values between 4800 and $6400 \mathrm{~W}$ for a high pressure of $14 \mathrm{bar}$. The cooling capacity is found to be between 1900 and $2200 \mathrm{~W}$ with COP between 0.32 and 0.36 . The actual results are found to lie between $75 \%$ and $85 \%$ of the calculated values.

Comparisons between actual and calculated values show that heat loss from the generator have a remarkable effect on the system performance, and the cooling capacity is also limited due to fixed condensing pressure, temperature limitations, or rising efficiency for rectification. A more efficient thermal system should have a higher COP and a lower total entropy generation. The entropy generation is used to identify and quantify performance degradation and the components responsible for it. The results show that the larger irreversibility is caused by spanning the largest temperature and dissipated thermal energy by heat transfer losses at the generator and evaporator.

\section{Acknowledgements}

An earlier version of this paper was presented at 2010 Asia-Pacific Power and Energy Engineering Conference.

\section{References}

[1] F. Ziegler, "Recent Developments and Future Prospects of Sorption Heat Pump Systems," International Journal of Thermal Sciences, Paris, Vol. 38, 1999, pp. 191-208.

[2] A. Apte, "Ammonia Absorption Refrigeration Plants the Ideal Refrigeration System for New Millennium," Transparent Energy Systems Private Limited, Pune, 2006. http://www. tespl.com

[3] K. C. Ng, T. Y. Bong, H. T. Chua and H. L. Bao, "Theoretical and Experimental Analysis of an Absorption Chiller," International Journal of Refrigeration, London, Vol. 17, 1994, pp. 351-358.

[4] A. Kececiler, H. I. Acar and A. Dogan, "Thermodynamics Analysis of Absorption Refrigeration System with Geothermal Energy: An Experimental Study," Energy Conversion and Management, London, Vol. 41, 2000, pp. 37-48.

[5] J. Chen and B. Andresen, "Optimal Analysis of Primary Performance Parameters for an Endoreversible Absorption Heat Pumps," Heat Recovery Systems and CHP, London, Vol. 15, 1995, pp. 723-731.

[6] A. Bejan, J. V. C. Vargas and M. Solokov, "Optimal Allocation of a Heat Exchanger Inventory in Heat-Driven Refrigerators," International Journal of Heat Mass Transfer, Vol. 38, No. 5, 1995, pp. 2997-3004.

[7] N. E. Wijeysundera, "Analysis of the Ideal Absorption Cycle with External Heat-Transfer Irreversibilities," Energy, London, Vol. 20, 1995, pp. 123-130.

[8] C. Wu, "Cooling Capacity Optimization of a Waste Heat Absorption Refrigeration Cycle," Heat Recovery Systems and CHP, Vol. 13, No. 4, 1993, pp. 161-166.

[9] C. Wu, "Specific Heating Load of an Endoreversible Carnot Heat Pump," International Journal of Ambient Energy, Vol. 14, 1993, pp. 25-28.

[10] K. C. Ng, H. T. Chua and Q. Han, "On the Modeling of Absorption Chillers with External and Internal Irreversibilities," Applied Thermal Engineering, Vol. 17, No. 5, 1997, pp. 413-425.

[11] H. T. Chua, J. M. Gordon, K. C. Ng and Q. Han, "Entropy Production Analysis and Experimental Confirmation of Absorption Systems," International Journal of Refrigeration, Vol. 20, No. 3, 1997, pp. 179-190.

[12] K. C. Ng, K. Tu and H. T. Chua et al., "Thermodynamic Analysis of Absorption Chillers: Internal Dissipation and Process Average Temperature," Applied Thermal Engineering, Vol. 18, No. 8, 1998, pp. 671-682.

[13] H. T. Chua, "Universal Thermodynamic Modeling of Chillers: Special Application to Adsorption Chillers," Ph.D. Dissertation, National University of Singapore, Singapore, 1998.

[14] H. T. Chua, H. K. Toh, A. Malek and K. C. Ng, K. Srinivasan, "A General Thermodynamic Framework for Understanding the Behavior of Absorption Chillers," International Journal of Refrigeration, Vol. 23, No. 7, 2000, pp. 491-507.

[15] H. T. Chua, H. K. Toh and K. C. Ng, "Thermodynamic Modeling of an Ammonia-Water Absorption Chiller," International Journal of Refrigeration, Vol. 25, No. 7, 2002, pp. 896-906. 
[16] "Thermo Physical Properties of Refrigerants," ASHRAE Handbook, 2005.

[17] R. Tillner-Roth and D. G. Friend, "A Helmholtz Free Energy Formulation of the Thermodynamic Properties of the Mixture $\{$ Water + Ammonia\}," Journal of Physical and Chemical Reference Data, Vol. 27, No. 1, 1998, pp.

\section{Nomenclature}

$\begin{array}{ll}\text { AFR } & \text { Ammonia fluid reservoir } \\ \text { COP } & \text { Coefficient of performance } \\ \mathrm{h} & \text { Specific enthalpy }(\mathrm{kJ} / \mathrm{kg}) \\ \mathrm{m} & \text { Mass flow rate }(\mathrm{kg} / \mathrm{s}) \\ \mathrm{P} & \text { Presser }(\text { bar }) \\ \mathrm{Q} & \text { Heat transfer rate }(\mathrm{W}) \\ \mathrm{RED} & \text { Refrigerant expansion device } \\ s & \text { Specific entropy }(\mathrm{kJ} / \mathrm{kg} \bullet \mathrm{K}) \\ S & \text { Entropy production rate }(\mathrm{W} / \mathrm{K}) \\ \mathrm{SED} & \text { Weak solution expansion device } \\ \mathrm{SFR} & \text { Solution fluid reservoir } \\ \mathrm{SHE} & \text { Solution heat exchanger } \\ \mathrm{T} & \text { Temperature }(\mathrm{K}) \\ \text { VST } & \text { Vertical sieve tray tower with complete con- } \\ \text { densation } & \\ W & \text { Work }(\mathrm{kJ}) \\ x & \text { Ammonia mass concentration }\end{array}$

$$
\text { 63-96. }
$$

[18] K. C. Ng, H. T. Chua and K. Tu, "The Role of Internal Dissipation and Process Average Temperature in Chiller Performance and Diagnostics," Journal of Applied Physics, Vol. 83, No. 4, 1998, pp. 1831-1836.

\section{Subscripts}

$\begin{array}{ll}\text { a } & \text { Absorber } \\ \mathrm{c} & \text { Condenser } \\ \mathrm{e} & \text { Evaporator } \\ \mathrm{g} & \text { Generator } \\ i & \text { Component numbering index } \\ \text { in } & \text { Inlet conditions } \\ \text { int } & \text { Internal } \\ \text { out } & \text { Outlet conditions } \\ \mathrm{P} & \text { Pump } \\ \mathrm{RED} & \text { Refrigerant expansion device } \\ \text { sc } & \text { Subcooler } \\ \mathrm{SED} & \text { Weak solution expansion device } \\ \mathrm{SHE} & \text { Solution heat exchanger } \\ \text { th } & \text { Theoretical value } \\ \alpha & \text { Phase numbering index } \\ \text { Superscripts } \\ \text { tot } & \text { Total value }\end{array}$

